\title{
Tramadol HCL: Preformulation Studies of Imperative Part of Formulation Design
}

Mohit Saini $^{1 *}$, Amit Kumar ${ }^{2}$, Jitender Malik², Pankaj Singh Painwal ${ }^{3}$, Bipin Prakash Tamta ${ }^{4}$

${ }^{1}$ Aroma College Roorkee, Haridwar (UK) India

${ }^{2}$ Smt. Manjira Devi Shikshan and Prashikshan Institute, Hitanu Dhanari, Uttarkashi, India

${ }^{3}$ R.V.Northland Institute, Gautam Budh Nagar, (UP) India

${ }^{4}$ Shree Guru Ram Rai Institute of Medical \& Health Sciences, Dehradun (UK) India

DOI: $10.36347 /$ sajp.2020.v09i09.002

| Received: 31.08.2020 | Accepted: 08.09.2020 | Published: 09.09.2020

*Corresponding author: Mohit Saini

\section{Abstract}

Original Research Article

Preformulation study is a part which is initiated formerly the new molecule is seeded. In a broader way, it pact with studies of physical, chemical, analytical, and pharmaceutical properties related to molecule and provides idea about suitable modification in molecule to show a better performance. Preformulation parameters study can be linked to production of effective, safer, stable, and reliable pharmaceutical formulation. Tramadol is an opioid pain medication used to treat moderate to moderately severe pain. The mechanism of action is not clear, even though the parent and metabolite of Tramadol binds to $\mu$-opioid receptors and results in weak inhibition and reuptake of nor-epinephrine and serotonin. In the present works generally goal of preformulation studies of Tramadol $\mathrm{HCl}$ is to engender information useful in developing stable and Bioavailable dosage forms.

Keywords: Preformulation study, Tramadol $\mathrm{HCl}$, Solubility \& analytical methods.

Copyright @ 2020: This is an open-access article distributed under the terms of the Creative Commons Attribution license which permits unrestricted use, distribution, and reproduction in any medium for non-commercial use (NonCommercial, or CC-BY-NC) provided the original author and source are credited.

\section{INTRODUCTION}

Preformulation study is the chief tread in the rational development of dosage forms of a drug substance. The study includes an examination of physical and chemical properties of a drug substance alone and with combined with excepient. The general endeavor of preformulation testing is to generate information helpful to the formulator in developing stable and bioavailable dosage forms that can be mass produced. Preformulation investigations are designed to deliver all necessary data especially physicochemical, physico-mechanical and bio pharmaceutical properties of drug substances, excipients and packaging materials [1]. These studies should focus on those physicochemical properties of the new compound that could affect drug performance and development of an effective dosage form. A systematic understanding of these properties may eventually provide a rational for formulation design, or sustain the need for molecular modification. The aim of this study was to establish some of the physicochemical properties such as solubility, melting point, $\mathrm{pKa}$, dissolution, assay development, stability in solution etc $[2,3]$.

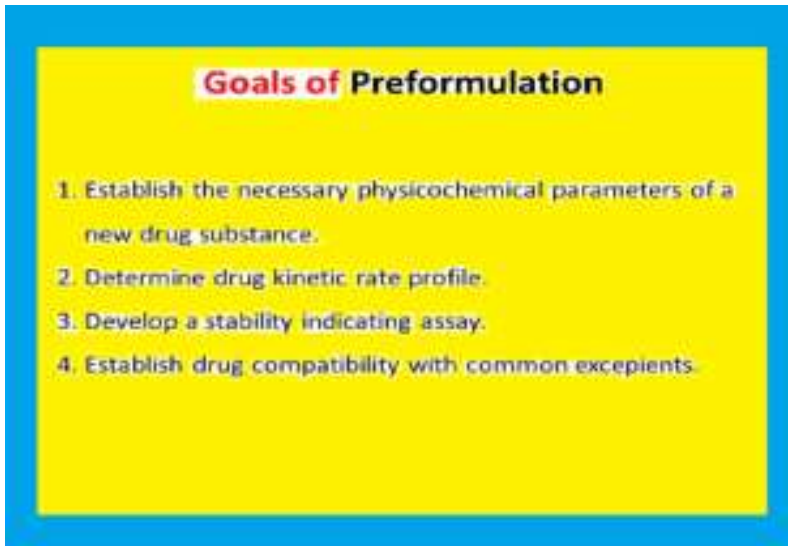

Tramadol hydrochloride, $( \pm) \quad$ cis-2[(dimethylamino) methyl]-1-(3-methoxyphenyl) cyclohexanol Hydrochloride [4]. Tramadol Hydrochloride is a narcotic like analgesic used in severe pain. Tramadol has inhibitory action on 5-HT2C receptor and even though the parent and M1 metabolite of Tramadol binds to $\mu$ opioid receptors and results in weak inhibition and reuptake of norepinephrine and serotonin. In several animal tests Tramadol-induced analgesia is only partially antagonized by the opiate antagonist naloxone [5]. 


\begin{tabular}{|l|}
\hline IUPAC Name \\
\hline Structure
\end{tabular}

In the present works a challenge was made to study preformulation parameters of Tramadol $\mathrm{HCl}$ which helps to produce information useful in developing stable and Bioavailable dosage forms.

\section{MATERIAL AND METHODOLOGY}

Procurement of Drug: Tramadol hydrochloride was obtained as gift sample from JubilantChemsys Ltd., Noida.

\section{Organoleptic properties}

Organoleptic properties of the drug sample were studied by visual inspection.

\section{Preformulation studies [8-16] \\ Identification of Drug \\ Melting Point Determination}

To determine the M.P. of drug powder, it was filled in a capillary tube with one end open and the other end closed and then the capillary was placed in a digital melting point apparatus.

\section{Solubility}

The drug was found to be freely soluble in water and in methanol, very slightly soluble in acetone, which matches the existing reference.

\section{Loss on drying}

The average LOD (\%w/w) and \% LOD were determined.

\section{Partition coefficient}

About $50 \mathrm{mg}$ of drug was dissolved in $50 \mathrm{ml}$ of distilled water and n-octanol separately and both the solution was mixed together by using wrist watch shaker for $30 \mathrm{~min}$. Then the solution was kept in a separating funnel until two phases separated. The aqueous phase was then filtered through the filter paper and was diluted 100 times. The absorbance of both the solutions was taken at $234 \mathrm{~nm}$ by using UV spectrophotometer. The concentration of drug was determined with the help of standard curve and partition coefficient was determined by following formula:

$$
\text { Partition coefficient }=\frac{\text { Concentration of drug in organic phase }}{\text { Concentration of drug in aqueous }}
$$

\section{FTIR spectroscopy studies}

FTIR (ATR Bruker, Germany) was used. The IR spectrum was obtained by scanning it in the range 4000-500nm and compared with the reference pharmacopoeia (IP-2014).

\section{Analytical Method}

A concentration $1.0 \mu \mathrm{g} / \mathrm{ml}$ solution of tramadol hydrochloride in distilled water was scanned. The scan report is shown in fig. no. 1 and the $\lambda \max$ was found to be $270 \mathrm{~nm}$.

\section{Preparation of standard curve in distilled water}

As described in experimental section, the different dilutions were analyzed in UVSpectrophotometer at $270 \mathrm{~nm}$ and the standard curve was plotted. The graph obeyed the Beer- Lambert's law, the regression equation of the curve is found to be $\mathrm{y}=$ $0.1613 x+0.0485$ and correlation coefficient is found to be 0.9999 , which reveal high precision of curve. This curve is further used for drug content analysis. 
UV-analysis of tramadol hydrochloride in phosphate buffer pH 7.4

A solution of tramadol hydrochloride in phosphate buffer $\mathrm{pH} 7.4$ of conc. $0.8 \mu / \mathrm{ml}$ was scanned. The $\lambda$ max was found to be $271 \mathrm{~nm}$.

\section{Preparation of standard curve in phosphate buffer} pH 7.4

The $\lambda \max$ is found to be $271 \mathrm{~nm}$. The graph obeyed Beer-Lambert's law at the range of $2-20 \mu \mathrm{g} / \mathrm{ml}$, the regression equation of the curve is found to be $\mathrm{y}=$ $0.1688 x+0.0057$ and correlation coefficient is found to be 0.9992 made the method suitable and precise for further analysis of drug during in- vitro release study.

Table 1: Preformulation Characteristics

\begin{tabular}{|c|c|c|}
\hline S. No. & Characteristics & Results \\
\hline 1. & Appearance & White, bitter, crystalline \\
\hline 2. & Melting Point & Melting Point was found to be $180^{\circ} \mathrm{C}-184^{\circ} \mathrm{C}$. \\
\hline 3. & Partition coefficient & 1.32 \\
\hline
\end{tabular}

Table 2: Solubility data of the drug in different solvents/ buffers

\begin{tabular}{|l|c|c|}
\hline Solvents & $\begin{array}{c}\text { Conc. } \mathbf{~ m g} / \mathbf{m l} \text { at room } \\
\text { temperature }\end{array}$ & Solubility \\
\hline Water & $30 \mathrm{mg} / \mathrm{ml}$ & Freely \\
Methanol & $22 \mathrm{mg} / \mathrm{ml}$ & Soluble \\
Acetone & $10.2 \mathrm{mg} / \mathrm{ml}$ & Freely \\
Phosphate & $>20 \mathrm{mg} / \mathrm{ml}$ & Soluble \\
Buffer pH & & Slightly \\
7.4 & & Soluble \\
& & Sparingly \\
& & Soluble \\
\hline
\end{tabular}

Table 3: Percent loss on drying of tramadol hydrochloride

\begin{tabular}{|c|c|c|c|c|c|}
\hline S. No. & $\begin{array}{l}\text { wt. of before } \\
\text { drying(gm) }\end{array}$ & $\begin{array}{l}\text { wt. of after } \\
\text { drying(gm) }\end{array}$ & $\operatorname{LOD}(\% \mathrm{w} / \mathrm{w})$ & $\begin{array}{l}\text { Average } \\
\text { LOD }(\% \text { w/w })\end{array}$ & $\begin{array}{l}\text { Limit of } \\
\text { LOD }(\% \text { w/w })\end{array}$ \\
\hline 1 & 1 & 0.9985 & 0.15 & \multirow{3}{*}{0.15} & \multirow{3}{*}{$0.1-0.5$} \\
\hline 2 & 1 & 0.9986 & 0.14 & & \\
\hline 3 & 1 & 0.9985 & 0.15 & & \\
\hline
\end{tabular}

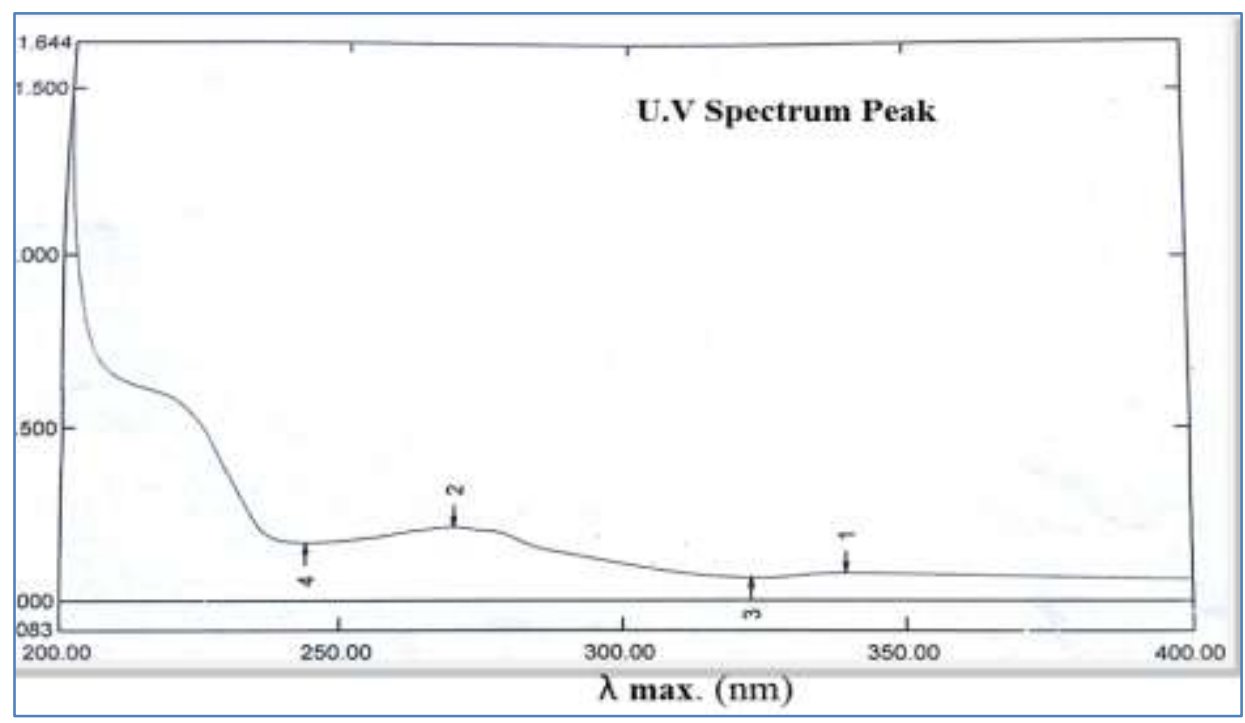

Fig.1: $\lambda \max$ determination (distilled water) 
Table 4: Standard curve data of tramadol hydrochloride in distilled water

\begin{tabular}{|c|c|c|}
\hline S. No. & Conc. $(\boldsymbol{\mu} / \mathbf{m l})$ & Absorbance \\
\hline 1 & 0.2 & 0.081 \\
\hline 2 & 0.4 & 0.112 \\
\hline 3 & 0.6 & 0.145 \\
\hline 4 & 0.8 & 0.180 \\
\hline 5 & 1.0 & 0.209 \\
\hline 6 & 1.2 & 0.241 \\
\hline 7 & 1.4 & 0.275 \\
\hline 8 & 1.6 & 0.308 \\
\hline 9 & 1.8 & 0.338 \\
\hline 10 & 2.0 & 0.371 \\
\hline
\end{tabular}

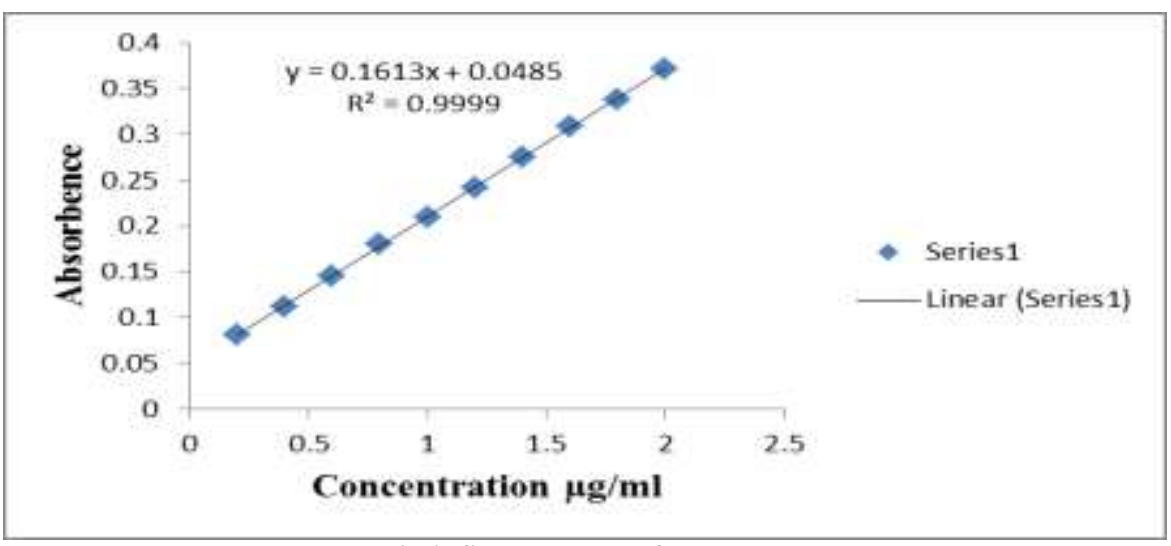

Fig-2: Standard cuve of Tramadol

Table-5: Standard curve data of tramadol hydrochloride in in phosphate buffer pH 7.4

\begin{tabular}{|c|c|c|}
\hline S. No. & Conc. $(\boldsymbol{\mu} / \mathbf{m l})$ & Absorbance \\
\hline 1 & 0.2 & 0.039 \\
\hline 2 & 0.4 & 0.072 \\
\hline 3 & 0.6 & 0.105 \\
\hline 4 & 0.8 & 0.140 \\
\hline 5 & 1.0 & 0.181 \\
\hline 6 & 1.2 & 0.210 \\
\hline 7 & 1.4 & 0.242 \\
\hline 8 & 1.6 & 0.272 \\
\hline 9 & 1.8 & 0.307 \\
\hline 10 & 2.0 & 0.345 \\
\hline
\end{tabular}

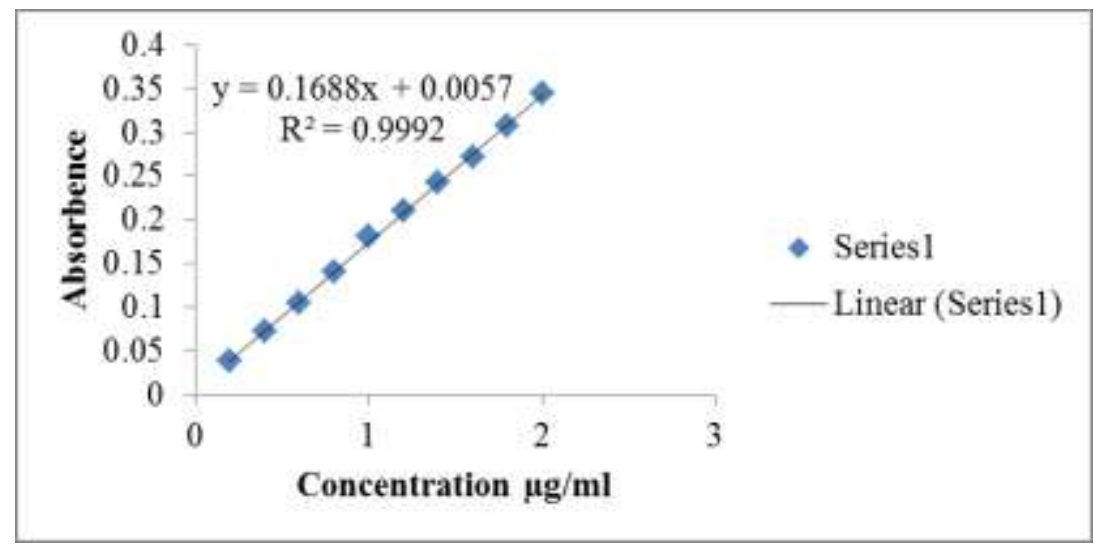

Fig-3: Standard curve of TH in phosphate buffer $\mathrm{pH} 7.4$ 


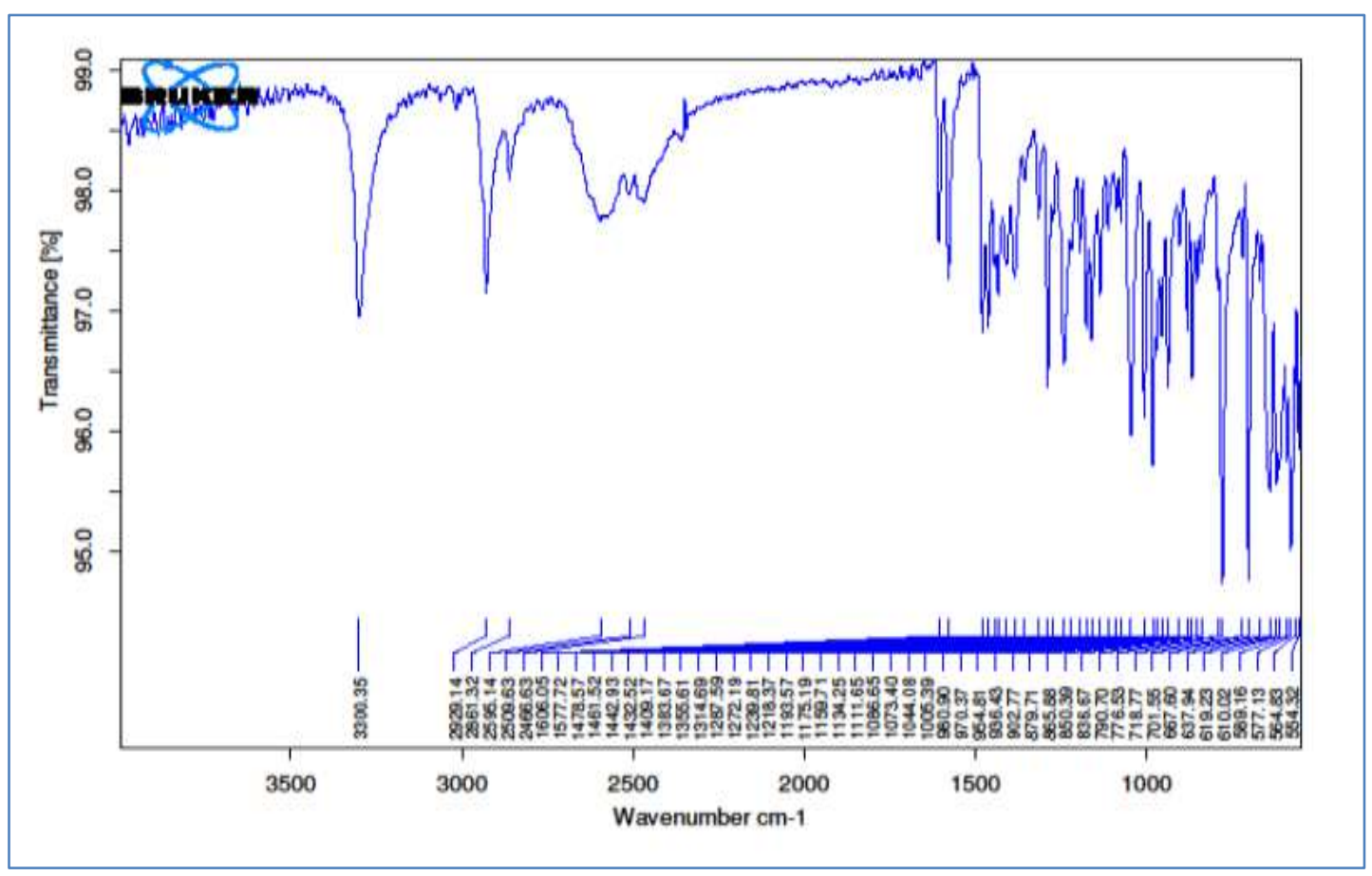

Fig-4: IR spectra of standard Tramadol

Table-6: Interpretation of IR spectrums

\begin{tabular}{|c|c|c|c|}
\hline Sample & Obtained peak values $\left(\mathbf{c m}^{-\mathbf{1}}\right)$ & Theoretical frequency $\left(\mathbf{c m}^{\mathbf{1}}\right)$ & Functional group \\
\hline \multirow{4}{*}{$\begin{array}{c}\text { Tramadol } \\
\text { HCl }\end{array}$} & 3100 & $3500-3100$ & Secondary Amines (-NH) Str \\
\cline { 2 - 4 } & 1462 & $1450-1600$ & $\mathrm{C}=\mathrm{C}(\mathrm{S})$ \\
\cline { 2 - 4 } & 2961 & $2960-2850$ & Methyl (-CH) Str. \\
\cline { 2 - 4 } & 938 & $900-1300$ & $\mathrm{C}-\mathrm{O}(\mathrm{S})$ \\
\cline { 2 - 4 } & 1040 & $1000-1410$ & Amine C-N(S) \\
\hline
\end{tabular}

\section{RESULTS AND DISCUSSION}

The in general purpose of the present work was to investigate preformulation studies of Tramadol $\mathrm{HCl}$ is to generate information useful in developing stable and Bioavailable dosage forms. Preformulation studies of drug were undertaken concerning melting point, solubility analysis, UV-spectrophotometric analysis and FTIR analysis to identify and assessment of purity of drug. Various Preformulation Characteristics were tabulated in table 1 . The partition coefficient of rutin was found 1.32 , which confirms the lipophilicity of the drug. The drug was found to be freely soluble in water and in methanol, very slightly soluble in acetone, which matches the existing reference. From the result reported in the table 3 revealed that the loss of drying of the drug is within range $0.1-0.5$. The analytical method for determination of drug was UV spectroscopy. The absorption spectral analysis showed the $\lambda_{\max }$ of Tramadol $\mathrm{HCl}$ at $270 \& 271$ $\mathrm{nm}$ in distilled water and phosphate buffer $\mathrm{pH} 7.4$ respectively (table 4-5 \& Fig.1-3). The calibration data and curve is shown in table no. 4 and figure no. 2 respectively. The result of UV-Spectrophotometrically analysis in phosphate buffer is shown in table no. 5 and figure no. 3. The FTIR spectrum, there was no variation in the Tramadol $\mathrm{HCl}$ peaks from the standard spectrum of IP 2014(fig 4).The result of interpretation of IR spectra was tabulated in table 6 . Preformulation studies revealed the purity of the drug. UV-spectrophotometric analysis of drug in distilled water and phosphate buffer $\mathrm{pH} 7.4\left(\mathrm{y}=0.1613 \mathrm{x}+0.0485, \mathrm{R}^{2}=0.9999\right.$ in distilled water and $\mathrm{y}=0.1688 \mathrm{x}+0.0057, \mathrm{R}^{2}=0.9992$ in phosphate buffer $\mathrm{pH}$ 7.4) revealed the suitability of the standard curve for further calculation.

\section{CONCLUSION}

The preformulation step is a fundamental fraction in establishing the properties of drug that will allow suitable risk assessment for development. Usually it begins all through the lead optimization phase, continues through predomination, and on into the early on phases of development. Hence, it is necessary that preformulation should be performed as carefully as possible to facilitate coherent decisions to be made. The preformulation study of Tramadol $\mathrm{HCl}$ is to make information useful in developing stable and Bioavailable dosage forms.

\section{REFERENCE}

1. Desu PK, Vaishnavi G, Divya K, Lakshmi U. An overview on preformulation studies. Indo american 
journal of pharmaceutical sciences. 2015 Oct 1;2(10):1399-407.

2. Karuppusamy C, Venkatesan P. Preformulation Parameters Characterization to Design, Development and Formulation of Miglitol Loaded Nanoparticles. Journal of Pharmaceutical Sciences and Research. 2017 Mar 1;9(3):326.

3. Kumar A, Kumar A, Malik JK. Preformulation studies of Drotaverine $\mathrm{HCl}$ : An integral part of formulation design. European Journal of Biomedical and Pharmaceutical Sciences. 2019;6(13):304-7.

4. United States Pharmacopoeia, 25 ${ }^{\text {th }}$ Edn., The United States Pharmacopoeial convention, Inc., Rockville, 2002, pp. 1821-1824.

5. Joel GH, Eds. In Goodman \& Gilman's The Pharmacological Basis Of Therapeutics, $10^{\text {th }}$ Edn., McGraw-Hill Medical Publishing Division. 2001; 1335: 1349-1361.

6. Budavari S, Eds., In. The Merck Index, 13th Edn., Merck \& Co., Inc., Whitehouse Station, NJ, 2001: 958,1163,1809.

7. Kathleen P., Eds., In; Martindale The Complete Drug Reference $32^{\text {nd }}$ Edn., Pharmaceutical Press, London, 1999; 622: 623-630.

8. Mehta RM. Processing of tablets, Pharmaceutics-1. Delhi: Vallabh prakashan. 2002:238-67.

9. Soni H, Singhai AK. Formulation and development of hydrogel based system for effective delivery of rutin. Int J Appl Pharm. 2013;5(1):5-13.
10. Himesh, Soni. Preformulation Studies of Tramadol $\mathrm{HCl}$ : Vital Part of Formulation Design. EJBPS. 2020; 7(1): 369-373.

11. Vijaya C, Raghavan. A practical handbook of physical pharmaceutics 1 edition' April. 1995: 4157

12. Singh S, Saini M, Malik JK, Kumar A. Analytical Method Development and Validation for Estimation of Silymarin in Tablet Dosage form by HPLC. Asian Journal of Applied Chemistry Research. 2020 May 19:22-31.

13. Kumar D, Kumar A, Malik JK, Semwal P. Formulation and evaluation of fast dissolving uncoated tablets of drotaverine HCl. System. 2019 Nov 21;4:5.

14. Kumar D, Kumar A, Malik JK, Semwal P. Process evaluation and in-vitro drug release study of fast dissolving uncoated tablets of Drotaverine $\mathrm{HCl}$ European Journal of Scientific Exploration. 2019;2(6):1-8.

15. Kumar A, Kumar A, Malik JK. Preformulation studies of Drotaverine $\mathrm{HCl}$ : An integral part of formulation design. European Journal of Biomedical and Pharmaceutical Sciences. 2019;6(13):304-7.

16. Bose A. Development and Optimization of fixed dose Antihypertensive combination drugs using double layer sustained release Microsphere Technology. Asian Journal of Chemistry. 2011, 23(9): 3883-3886. 